\title{
Mitteilung
}

Projektgruppe/Fachkreis: Technische Strömung

\section{Experimental simulation of the human respiration system}

\author{
Andreas Kohl, Pascal Lange, Daniel Schmeling \\ Deutsches Zentrum für Luft- und Raumfahrt (DLR), \\ Institut für Aerodynamik und Strömungstechnik \\ Bunsenstraße 10, 37073 Göttingen, e-mail: pascal.lange@dlr.de
}

Keywords: Indoor air quality, breathing thermal manikin, $\mathrm{CO}_{2}$ distribution, passenger comfort, ventilation efficiency

Research and development activities in the overall context of improving indoor environmental quality (e.g. buildings, trains, cars etc.) have been in the interest of scientists and manufactures for many decades. Besides the thermal conditions, the indoor air quality affects the comfort, health and productivity of humans [1]. Modern passenger trains are already taking this aspect into account by adjusting the volume flow rate of the supplied fresh air based on interior $\mathrm{CO}_{2}$ values. The rapidly developing situation of the corona pandemic in 2020 also leads to the fact that studies regarding air quality, air pollution level and airborne transmission of infectious agents become more and more relevant. Through the interaction of different flow mechanisms caused by natural convection around the human body, the human's expiration and the ventilation system affect the air's enthalpy level and the chemical parameters [2]. Hence, a mobile respiration device for thermal manikins was developed and tested at the DLR in Göttingen in order to simulate the human respiration process. The device provides realistic breathing volume flows and frequencies and can be connected to existing thermal manikins. Thanks to an integrated system that analyzes the air and a dosing system based on local sensors and a solenoid valve, the exhaled air can be enriched with $\mathrm{CO}_{2}$ to simulate realistic $\mathrm{CO}_{2}$ emissions of a human. In this context, any gas can be added to the system, thus allowing the investigation of airborne dispersal paths and ventilation efficiencies by means of tracer gas measurement techniques.
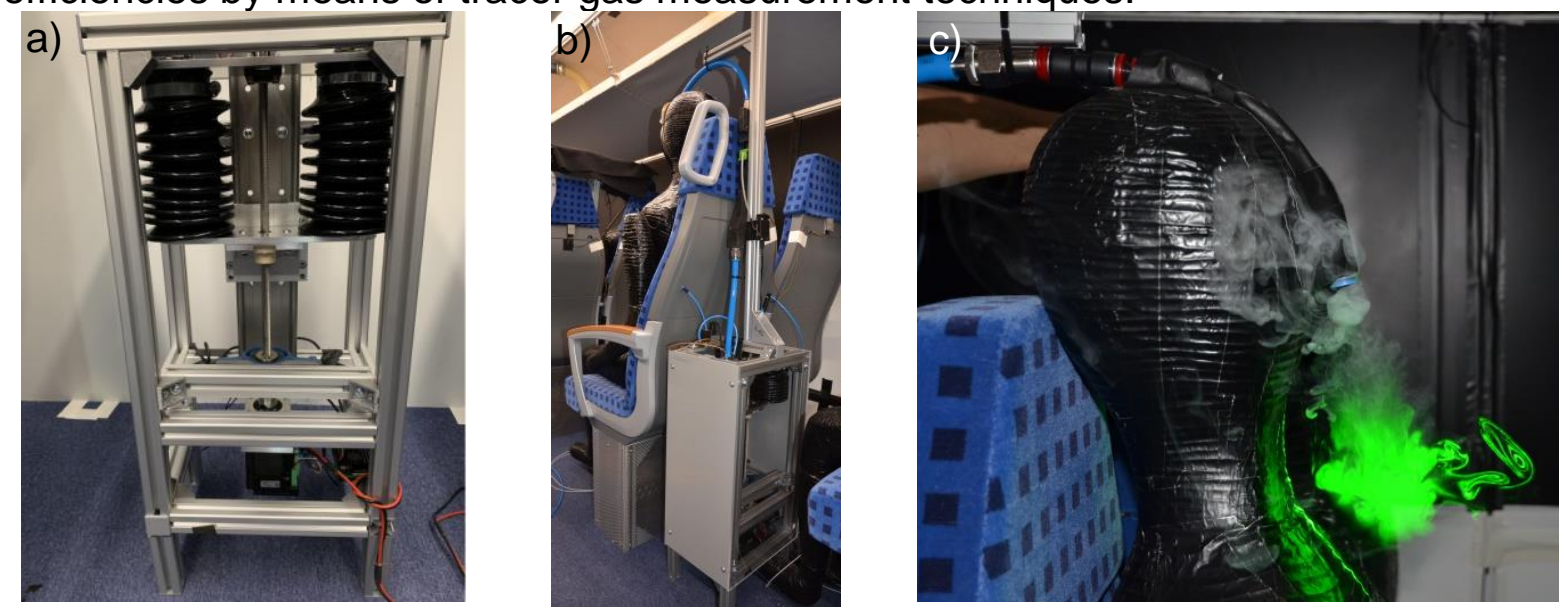

Figure 1: Mobile respiration system. a) Front view showing the individual components. b) Installation and connection to a thermal manikin in a generic train cabin. c) Visualization of exhalation process.

The device is based on two air actuators representing the lung, see Figure 1a). A stepper motor in combination with a threaded spindle and linear slides simulates the inhalation and exhalation process. The air analysis system is integrated in the left actuator, 
while the right actuator provides the gas dosage system. All parts are enclosed by a housing made of aluminum profiles. The device can be connected to a manikin's face via a tubing system, which contains the volume flow control system. Thanks to the design and dimensions of the respiration system (see Figure 1b), it is possible to position it close to the manikin (i.e. behind the seats in a cabin). Figure 1c) depicts a flow visualization of the exhaled air using laser light and smoke.
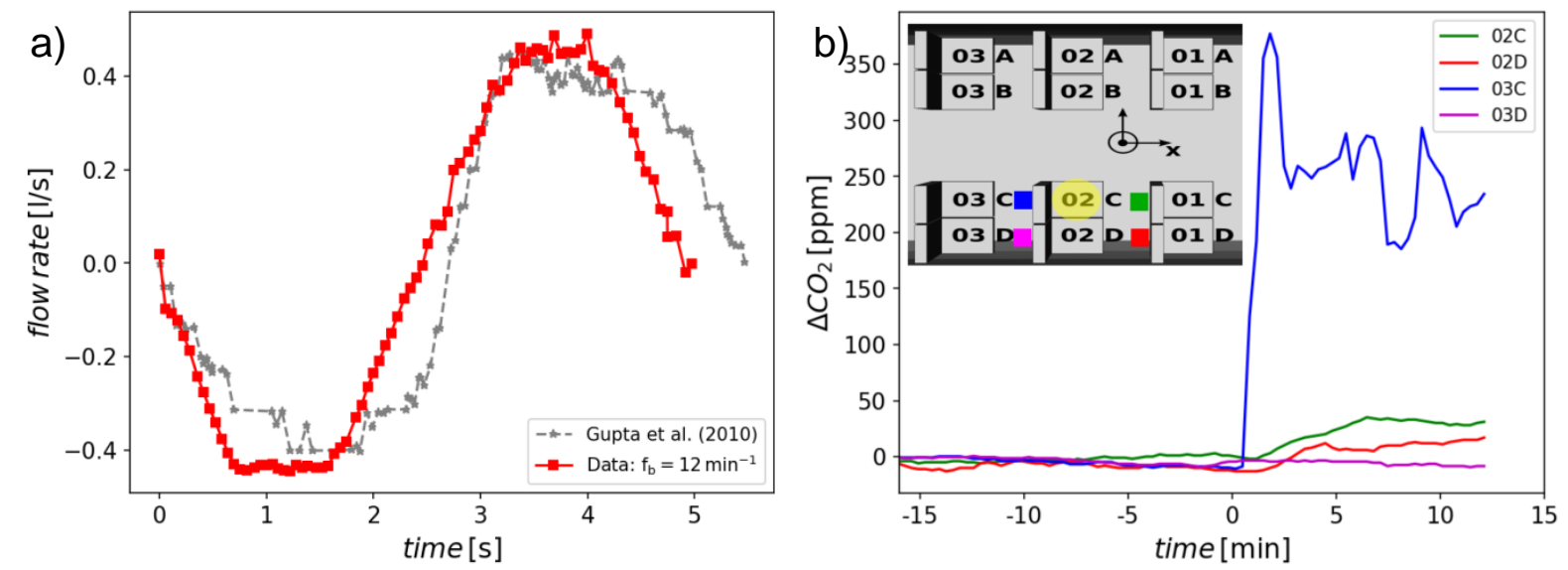

Figure 2: Validation results. a) Mean breathing flow rate compared to the data given in [3]. b) $\mathrm{CO}_{2}$ distribution measured within a generic train laboratory.

In a first validation phase, the parameters for the stepper motor were determined in order to simulate realistic breathing volume flow rates. Figure $2 a$ ) shows the comparison of mean flow rate values (red data points) measured with the mobile respiration device for a breathing frequency of $f_{b}=12 \mathrm{~min}^{-1}$ and data given in [3] (grey data points). The latter analyzed the human breathing volume (rest respiration for sitting people) of 25 test persons using a spirometer. In general, the breathing volume flow is characterized by a sine function. While the amplitude of both data sets is quite similar, the period duration (represents breathing time) of the experimental data is slightly shorter compared to the data from the literature. This means, some additional minor adjustments in terms of the stepper motor are required. In a further study, the $\mathrm{CO}_{2}$ injection was tested in a generic train lab, as described in [4]. Here, the breathing system was installed at seat $02 \mathrm{C}$ (see yellow circle in Figure $2 \mathrm{~b}$ ) and the adjoining seats were equipped with local sensors (colored rectangles). The resulting $\mathrm{CO}_{2}$ values after starting the breathing system (at $t=0 \mathrm{~min}$ ) are shown in Figure $2 \mathrm{~b}$ ). The measurements revealed that the highest $\mathrm{CO}_{2}$ values can be found on the seat right behind the source, whereas the values on the neighboring seat (02D) are only slightly increased. This can be attributed to the flow pattern caused by the installed cabin displacement ventilation system.

More information about the breathing system as well as a detailed presentation and analysis of the validity measurements results will be part of the full paper.

\section{References}

[1] Dorgan B., Dorgan E., Kanarek M., Willman A., 1998, Health and productivity benefits of improved indoor air quality, ASHRAE Transactions 104, p. 658

[2] Melikov A., 2004, Personalized ventilation, Indoor Air 14, p. 157 - 167

[3] Gupta J., Lin C-H., Chen Q., 2010, Characterizing exhaled airflow from breathing and talking, Indoor Air 20/1, p. $31-39$

[4] Schmeling D., Bosbach J., 2017, On the influence of sensible heat release on displacement ventilation in a train compartment, Building and Environment 125 , p. $248-260$ 